\title{
Integral Design Process of Flexible MANUFACTURING SystemS
}

\author{
MULC, T., CIGLAR, D., STAROVEŠKI, T. \& KLAIĆ, M.
}

Abstract: Today, as never before, the development of new technologies and globalization raise the level of demand for production systems through a higher degree of intelligence of production equipment in terms of adaptation, communication and interaction with the environment. Significantly more efforts need to be focused on innovation and quality. In early stages of designing of manufacturing systems, the expected variability of the process should be anticipated based on the product configuration and the technology that ensures the product of the expected level of quality and quantity. Therefore, an integral view of the process at early stages of designing of a flexible manufacturing system is crucial in making strategic decisions that determine the basic features of the system in terms of flexibility, productivity and quality. This article describes the process of creating and designing of FMS from the initial product requirements, through planning engineering activities on the development of a production system that will meet the needs and production of products in the desired quantity and quality.

Key words: Technology, Integral Design, Special Purpose Machine Tool, Flexible manufacturing systems (FMS)
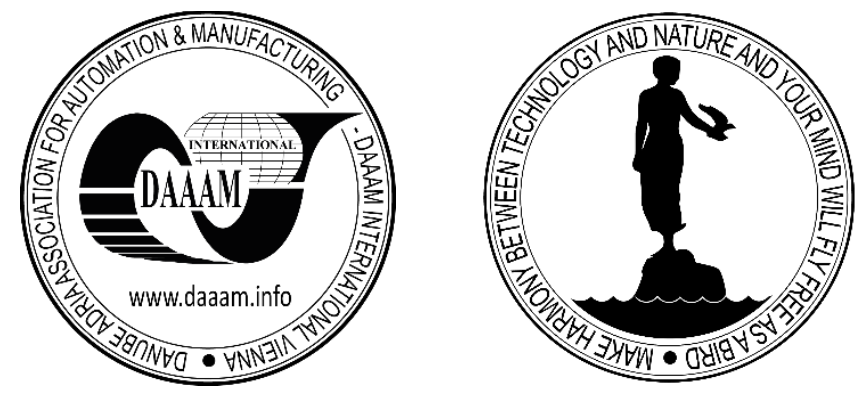

Authors' data: Dr. Sc. Mulc, T [ihomir] *, SAS-Strojogradnja, Domovinskog rata 1, 23000 Zadar; Univ.Prof. Dipl. Ing. Dr. Ciglar, D [amir] *; Univ.Prof. Dipl. Ing. Dr. Staroveški, T [omislav] *; Dr. Sc. Klaić, M [iho] *; University of Zagreb, Faculty of Mechanical Engineering and Naval Architecture, Ivana Luciča 5, 10005, Zagreb, tihomir@sas-strojogradnja.hr,dciglar@fsb.hr, tstaroveski@fsb.hr, mklaic@fsb.hr

This Publication has to be referred as: Mulc, T[ihomir]; Ciglar, D[amir]; Staroveski, T[omislav] \& Klaic, M[iho] (2021). Integral Design Process of Flexible Manufacturing Systems, Chapter 12 in DAAAM International Scientific Book 2021, pp.139-162, B. Katalinic (Ed.), Published by DAAAM International, ISBN 978-3-902734-31-0, ISSN 1726-9687, Vienna, Austria

DOI: $10.2507 /$ daaam.scibook.2021.12 
Mulc, T.; Ciglar, D.; Staroveski, T. \& Klaic, M.: Integral Design Process of Flexibl...

\section{Introduction}

An increase in individuality, which is associated with an increase in the variety of products while increasing the complexity of products, as well as increasing productivity and cost-effectiveness of production necessarily leads to automation and autonomy of individual production components and their integration into complex production structures composed of CNC machines, robotic systems, computer controlled transport systems, numerically controlled measuring machines, including the development of appropriate software tools for design, calculation, analysis, management and monitoring. Thus, the manufacturing system becomes a structurally integrated production complex with the aim of fulfilling production tasks in terms of quantity, quality and competitive price. Today's production structures can fulfill various production tasks, which within a group of products with similar geometric and technological features is a necessity in changing market conditions (Kaut 2018) (Haar 2019).

The choice of the optimal structure of production systems for a given task in the preliminary design phase is one of the most difficult problems and depends on the type, range, complexity of products and technological processing procedures. The basic bases for process design are:

- product range and quantity - product batch size

- geometric data (shape and dimensions, manufacturing accuracy, surface treatment),

- product function and special requirements - product life etc.

During the process of flexible manufacturing systems designing, the fundamental task is to find the optimal structure of the FMS (Flexible Manufacturing System) and an efficient way to produce different parts according to the production needs.

The efficiency of the production system significantly depends on its spatial structure, which is greatly influenced primarily by technological processes and economic frameworks: product range and quantities, the degree of structural and technological similarity of products, shape, dimensions and processing tolerances, product life, etc. (Koren 2010).

In early stages of a production system designing, the required input data are often unclear or incomplete and change as the project develops according to customer preferences, technical feasibility, and financial framework. During the creation of the system it is very important to recognize this fact and be prepared to ensure the greatest possible flexibility and modularity, scalability and stability throughout the entire system life cycle. This is a great challenge for both the designer and all participants in the process. There are two basic tasks when designing an FMS:

- design the best possible system that meets the above requirements.

- manage the system in the best possible way to meet certain conditions.

Both aspects must be considered at an early stage in the strategic formation of the production system. 


\section{Basic features of FMS and general structure}

Each production system, if well designed, must ensure the quantity, quality and variability of the product within its structure. Large amount of data, variability of the production program, high interdependence, stochasticity of processes still make designing of production systems a great economic and intellectual challenge for both designers and customers. Over time, several different production structures have been identified, some of which with their characteristics are presented in the following table.

\begin{tabular}{|c|c|c|c|}
\hline \multirow[t]{2}{*}{ SYSTEM FEATURES } & $\begin{array}{c}\text { MODELS OF } \\
\text { MANUFACTURING } \\
\text { SYSTEMS } \\
\end{array}$ & \multirow[b]{2}{*}{ Flexible systems } & \multirow[b]{2}{*}{ Reconfigurable systems } \\
\hline & Dedicated systems & & \\
\hline \multicolumn{4}{|l|}{ Production program } \\
\hline product range & variety, limited & & \\
\hline batch sizes (quantity) & large - medium & small - medium & large - medium - small \\
\hline Dynamic & high - continuous & $\begin{array}{l}\text { small - continuous / } \\
\text { discontinuous }\end{array}$ & large - medium - small - continuous \\
\hline \multicolumn{4}{|l|}{ Production equipment } \\
\hline typ & specialized, special & universal, specialized & reconfigurable, specialized \\
\hline flexibility & limited & high & adaptable \\
\hline Productivity & high & limited & medium, adaptable \\
\hline Layout & homogenous & inhomogeneous & changeable and adaptable \\
\hline $\begin{array}{l}\text { Number of operations at } \\
\text { workplace }\end{array}$ & 1 & $>1$ & $\geq 1$ \\
\hline \multicolumn{4}{|l|}{ System efficiency } \\
\hline technical efficiency & $\geq 0.75$ & $\geq 0.75$ & $\geq 0.85$ \\
\hline economy efficiency & $\geq 0.80$ & $\geq 0.80$ & $\geq 0.90$ \\
\hline
\end{tabular}

Tab. 1. Characteristics of manufacturing system models (Vukovic et al., 2010)

Each production structure has its advantages and disadvantages. Main features of the selected structures are:

\section{Dedicated FMS:}

- Determined by the production constraint of workpiece types

- All parts produced in the system are known in advance

- The workpiece family is based on geometric similarity

- The machines are designed for specific processes so as to increase the production range

\section{Arbitrary organised FMS:}

- the workpiece family is large with actual variations in configurations,

- introduction of new workpieces is foreseen,

- it is much more flexible than dedicated FMS 
- use of general purpose machines

- production of workpieces in different process sequences

- high-tech control systems

Reconfigurable systems are a compromise between the first and the second system. The main features of production systems in addition to quality are productivity and flexibility. Each of these systems has its advantages and disadvantages, and each system is intended for a specific area of operation (Mehrabi et al., 2000), (Mehrabi et al., 2002), (ElMaraghy, 2005). The higher is the productivity, the less is flexibility. Each of these FMS structures has its limitations in terms of flexibility as a basis for adaptability to market conditions. It can be emphasized that there are three levels of production flexibility of FMS:

\section{Basic flexibility}

- Machine flexibility is the ease with which a machine can perform various operations.

- Material handling flexibility is a measure of the ease with which different types of products can be transported and properly positioned with different machine tools in the system.

- Operation flexibility is a measure of the ease with which an alternative sequence of operations can be used to process workpieces.

\section{System flexibility}

- Volume flexibility measures the ability of the system to operate profitably at different capacities on an existing workpiece type.

- Expansion flexibility is the ability to build systems and gradually expand it.

- Routine flexibility is a measure of alternative paths that workpieces can effectively follow through the system for a given process plan.

- Process flexibility is a measure of the amount of workpieces types that can be produced without any setup.

- Product flexibility is the amount of different types of products that can be produced in a system with minimal set-ups.

\section{Aggregate flexibilities:}

- Program flexibility - the ability of a system to operate for a reasonably long period without external intervention

- Production flexibility - the range of set types of workpieces that the system can produce without significant investment in capital equipment

- Market flexibility - the ability of a system to adapt effectively to changing market conditions.

Increase in flexibility raises the level of system complexity, which significantly increases investment costs and extends the time to achieve full productivity and optimal performance. Huge capital costs and a slow capital recovery process are limiting 
factors in the wider application of FMS. Therefore, the level of possible flexibility and the framework in which the project develops are determined at an early stage when making strategic decisions.

\subsection{General structure of FMS}

FMS is a highly automated processing system that has a group of process workstations interconnected by a system for automatic handling of materials from the storage system with full control with distributed control systems. The range of product types and quantities can be adjusted to meet changing market requirements, enabling digital integration of machines, products, parts and manufacturing processes, including a range of industrial process control systems, measurement and control technologies, optimized devices and advanced energy cost reduction solutions. Finding the optimal and suitable structure of a reliable flexible manufacturing system for different production and product requirements is a big challenge.

Each flexible manufacturing system is basically unique and specially designed for a specific customer or group of products, but there is a general structure of the constituent components that creates the largest number of FMS, Figure 1.

FMS: Structure
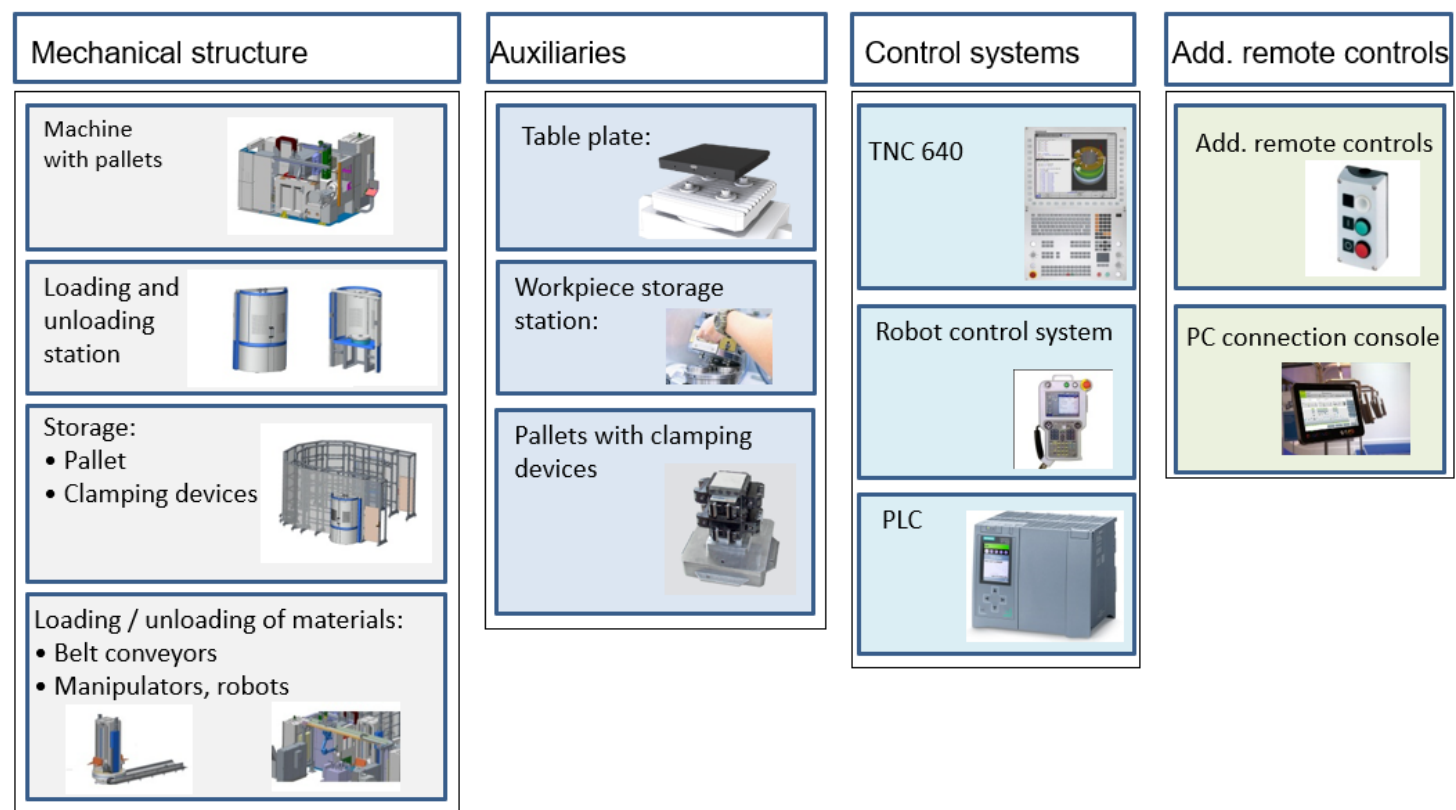

Robot control system
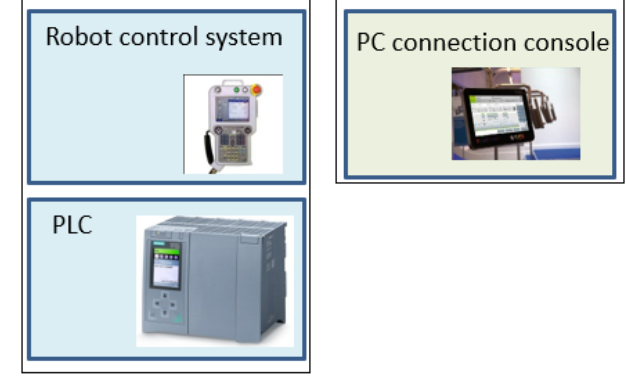

\section{(1)}


Mulc, T.; Ciglar, D.; Staroveski, T. \& Klaic, M.: Integral Design Process of Flexibl...

The complexity of all processes, their interdependence and uncertainty, timeliness and continuous flow in many practical situations, require a certain level of simultaneous prediction of different aspects of the system. This primarily refers to clamping devices, the flow of materials and tools, and logistics, which are limiting elements in the automation process. Defining the concept of the space composition of the constituent components necessary for the development of targeted production is the basic task for designers, technologists and investors (Abele et al., 2007).

\subsubsection{Designing of spatial structure of FMS}

Among the first activities, after the technological analysis of the process, the capacitive sizing of the production system is carried out as a basis for the creation of the spatial structure. In this analysis, it is necessary to determine the number of machines and other elements of the production system in order to ensure the production of the required quantity of products. The basic source of data for capacitive sizing of the production system is the technological process of making the part which determines the sequence of operations, the necessary tools, modes and duration of individual operations. When this is known, the number of elements of the production system is determined.

This is followed by the spatial structuring of the FMS and the analysis of the flow of material, energy and information. The load or time-of-use of a flexible manufacturing system directly depends on the layout of the processing units, the transport of tools and materials, and the measuring devices and washing machines. A flexible manufacturing system is justified if its performance is maximum, ie if there are no downtime and waiting at stations. For the correct installation of a flexible manufacturing system, it is necessary to monitor the time of production of parts depending on product quantity, material flows and information.

\subsection{FMS controls and logistics}

Controls of a flexible production system should enable the optimal functioning of all elements of the production system in terms of achieving of the set goals. Information processing in the FMS control system is distributed between multiple computers, at different control levels. In order to ensure flexibility and a high level of integration in the architecture of the FMS control system, it is necessary to decompose the control system into subsystems and the subsystems into modules during its designing. Each system should have a database that is structured and designed to be independent and focused on its areas of operation. There is an exchange of information between individual systems in the FMS so that each system performs its task at the right time, and the logistics program coordinates all activities.

The flow of information within the FMS comes from CAD, drawings through CAM simulations and activity planning, signal distribution and autonomous execution of individual commands. Each system is autonomous within its specific tasks. When integrating all components of the FMS with the process computer, the distribution of control tasks and data is possible. Information is processed at three levels:

- at the upper, highest level there are functions necessary for controlling of the production system and belonging to the organizational area (IT technology); 
- at the intermediate level information is processed by a control computer for each individual element in the system;

- at the lowest level there are the control functions associated with the processing (operational level).

Thus, control is organized hierarchically. Decisions at different levels take place in different time scales, from a few days to milliseconds. At each lower level, the number of details and the speed of communication increase. When receiving feedback from the second level, the situation at each level is optimally taken into account in real time. The highest level accepts short-term real-time production control requirements, and the lowest level issues orders to direct machine controllers. Each level issues commands to the target level and receives feedback on performance.

Therefore, control systems must be interconnected to exchange the necessary information with each other. This involves harmonizing a series of protocols and establishing various types of interfaces. The system is designed in such a way that the flow of information travels through the system $\neg$, and distribution of information and materials is carried out in accordance with the needs of the product. All systems are interconnected and represent an integral whole through the software part that is superior to its subsystems. This requires planning of all activities in the process, ie logistics. Logistics integrates planning, organizing, managing and controlling of the flow of materials, people, energy and information in systems. It seeks to find methods for optimizing these flows in order to achieve an economic effect, or optimal management of the production process. The process of flexible production planning includes a number of work processes such as:

- production planning,

- capacity planning,

- material planning,

- tool planning,

- transport planning.

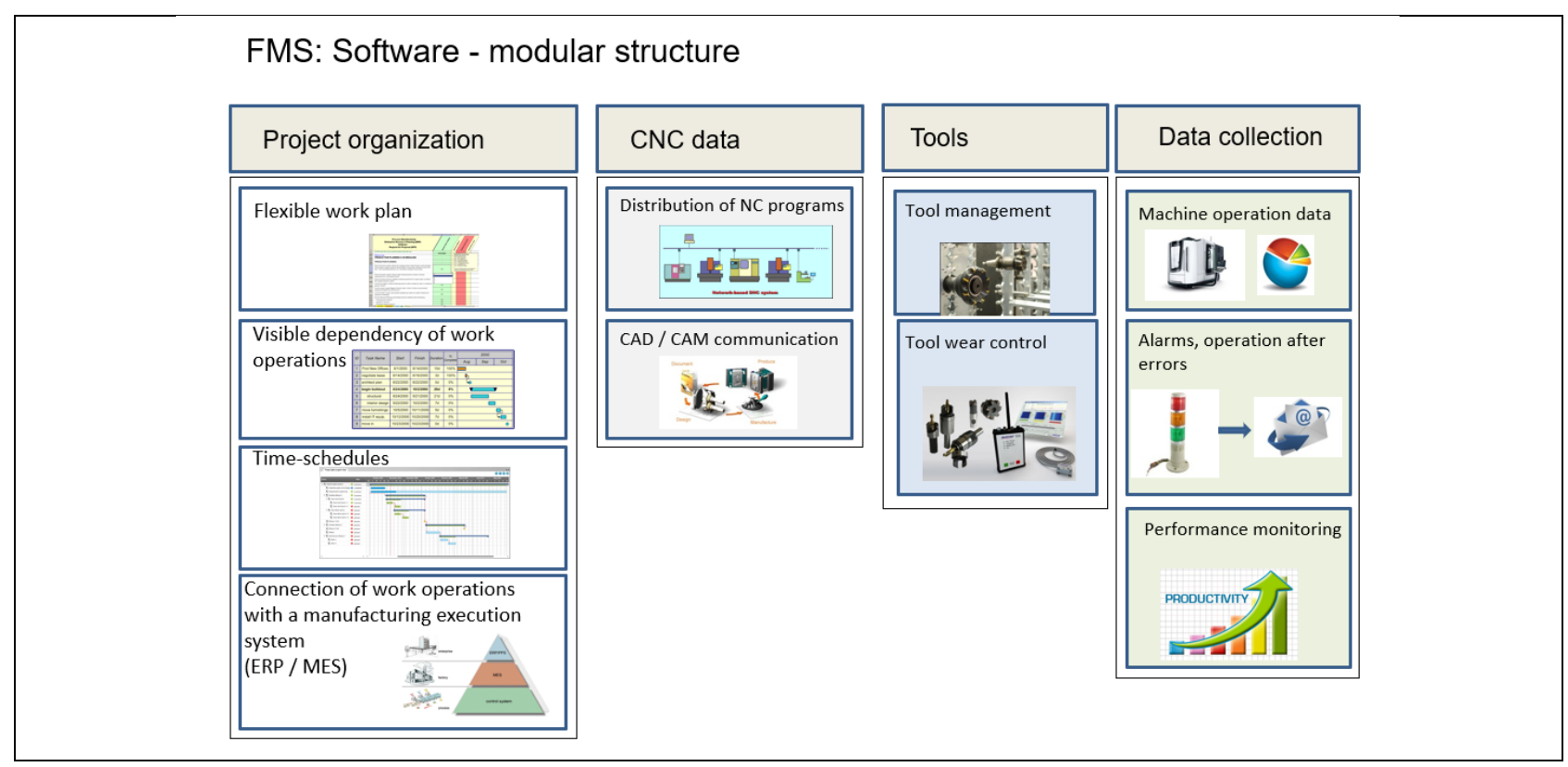

Fig. 2. Logistics program for control and management of FMS (Brochures, Soflex) 
Mulc, T.; Ciglar, D.; Staroveski, T. \& Klaic, M.: Integral Design Process of Flexibl...

The structure of general modules of Logistic Monitoring Software is shown in Figure. 2 .

The program consists of several characteristic modules:

\section{Project organization}

- Work plan,

- Visible dependence of work operations,

- Schedules,

- Communication with other software,

\section{CNC data}

- Distribution of NC programs,

- CAD / CAM communication,

\section{Tools}

- Tool management,

- Tool wear monitoring,

\section{Data collection,}

- Monitoring,

- Alarms,

- Statistical data.

\section{Logistics software knows the following basic communication sequences:}

- Transport orders for pallet processing,

- System status,

- Alarm and warning messages.

In automatic mode, the logistics program completely controls the automated production processes. It activates the supply of workpieces to the machines and initiates the start of automated processing. Automatic mode also includes work at loading / unloading stations where workpieces are fed into or out of the production system. If a storage station or buffer space is available, the logistics software activates the temporary stock storage when work stations are occupied and manages the storage allocation as well as the stock and workpiece carriers (management of device pallets, pallet shuttles and pallets for workpieces, pallets for material).

If direct transport to the intended machine or workstation is not possible, the logistics software generates a transport for the temporary storage of the workpiece or pallet, managing all warehouse groups. It supports default selection of "free" storage space. "Free" choice of storage means that there is no limitation on storage space and that items can be stored anywhere, regardless of their size. Alternatively, you can set a "fixed" storage position assignment. This means that each object is assigned a permanent storage location. 
The entry and exit of workpieces into the production system usually takes place via loading and unloading stations (manual workstations), the delivery of workpiece is automatically controlled by logistics software. For systems without loading and unloading stations, the software supports direct loading and unloading from storage locations through automated identification processes or manual booking processes. The clamping and unclamping processes are usually performed at an external setting station.

Efficient control of flexible production requires analysis of feedback data in order to make management decisions in real time. All the data obtained from these analyzes is needed for product planning, for control of machines, robots, transport systems, etc., and also for the analysis of system performance, Figure 3.

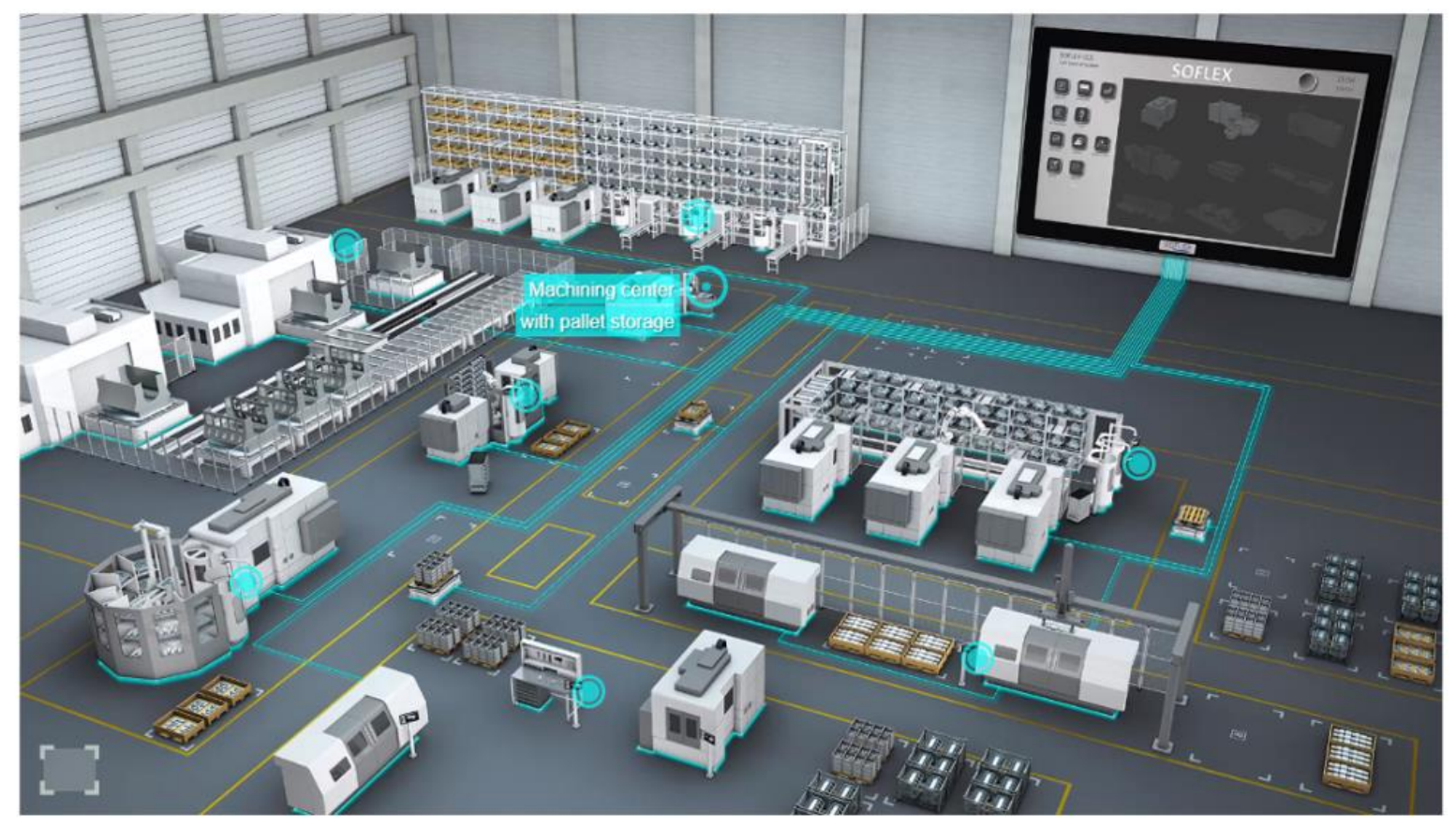

Fig, 3. Network communication structure in FMS (Brochures, Soflex)

\subsection{Diagnostics and monitoring of FMS}

In FMS, a large number of variables need to be maintained within narrowly defined limits in order for the system to operate stably and the quality of products to be high. Monitoring, diagnosing, and optimizing process management systems play a key role in ensuring process work tasks. Their main purpose is to monitor the process, detect and diagnose failures and downtime, and preventive monitoring. By applying modern software tools, it is possible to analyze the operation of processes and management systems, determine process states and optimize the parameters of management systems. This ensures more stable process management, higher product quality and optimal process operation. The general tasks of diagnostics of flexible manufacturing systems are:

- monitoring the state of the technological process and all involved auxiliary actions in the process (transport, measurement, washing, storage, etc.),

- monitoring the general condition of the hardware and software of all systems. 
Mulc, T.; Ciglar, D.; Staroveski, T. \& Klaic, M.: Integral Design Process of Flexibl...

Both levels of supervision are necessary for the optimal and stable operation of the FMS. The question about the amount of information, the kind and type of controls, monitoring and process control often arises. On the one hand, more information should improve the quality of the process, but increase in the number of checks can actually reduce quality if they are not performed properly and in the right places. Each module of the process is controlled autonomously in the part of the activity that it performs.

\section{An integral approach to FMS design by example}

\subsection{General assumptions and input data}

The process of designing of FMS implies multilevel knowledge, on the one hand, of the process, and on the other hand, of the principles of design within the framework of actual financial capabilities. Individual steps and procedures can be optimized, but the basic spatial structure must be consistent with current and future production goals. Specific requirements may relate to the future integration of machines into adaptive systems, and the spatial structure should allow for the following:

- Openness and modularity of technical and technological solutions,

- Openness of the control system,

- Modularity and extensibility of software solutions.

During the process of designing of flexible manufacturing systems, various decisions are made that determine the system configuration and the degree of automation and autonomy of the system. As previously emphasized, the process of creating of a dedicated flexible system is based on a series of input parameters:

product range (prismatic, rotary), annual quantity, quality,

- technological complexity of workpieces, geometric complexity, types of processing, dimensions and weight of parts

- shapes and material of workpieces,

- possibilities of forming groups of similar parts,

\section{available space,}

\section{market requirements for all relevant characteristics necessary for successful} product placement,

- product life,

- profitability of production.

As the first and necessary step in the formation of the system is a detailed technological analysis of products and analysis of processing conditions, (Hermaste, A et al., 2014), then the design of a flexible manufacturing system consisting of the following steps:

\section{Selection of a machine type,}

- Kinematic structure of the machine, working area, dimensions, load capacity, positioning accuracy, power and spindle speed, tool type, tool capacity in the magazine, number of controlled axes, pallet change system, 


\section{Selection of the number of machines,}

- Determining the number of machines that ensure the production capacity for required type and quantity of product,

\section{Selection of a material handling system,}

- System type and distribution of material flow,

- Type of system for automatic change of workpieces and positioning accuracy,

- Pallet dimensions, number of pallets,

- Clamping devices,

- principles and methods of product clamping,

- number of clamps,

- number of clamping devices,

- Transport systems - manipulators, robots, AGV vehicles,

\section{Selection of storage and warehousing systems,}

- Workpiece storage system - warehouses, intermediate storage,

- Pallet storage system,

- Number of input and output stations,

\section{Selection of FMS type and configuration}

- Machine configuration,

- Transport system configuration,

- Storage system configuration,

\section{Selection of management, control and monitoring system.}

Figure 4. shows the process of designing of a manufacturing system with input and output variables. Already at an early stage, it is necessary to know a number of input and output parameters that determine the structure and shape of the FMS, i.e. an integrated approach to the analysis of equipment and process is needed at an early stage when defining the system. The general features that define the basic structure of the future FMS are:

- Characteristics of parts, technology and tools,

- Characteristics of machines that can perform technological tasks,

- The number of machines in the system largely depends on the required capacity, ie the number of workpieces produced per unit of time,

- The material handling system depends on the workpiece, the dimensions and weight of the workpiece, the type of accessories and the storage system,

- The storage system depends on the type of material handling system, the dimensions of the workpieces, the number of devices.

- The size of the storage system that must ensure autonomous production in a given period, 
Mulc, T.; Ciglar, D.; Staroveski, T. \& Klaic, M.: Integral Design Process of Flexibl...

- Spatial structure of FMS. The appearance and shape of a flexible manufacturing system depends on the type of material handling system, workpiece storage systems, control system ....,

- Control system structure.

This data are used in the database to analyze the influence of various parameters on the structure of the system, i.e. in selecting the most suitable and optimal structure.

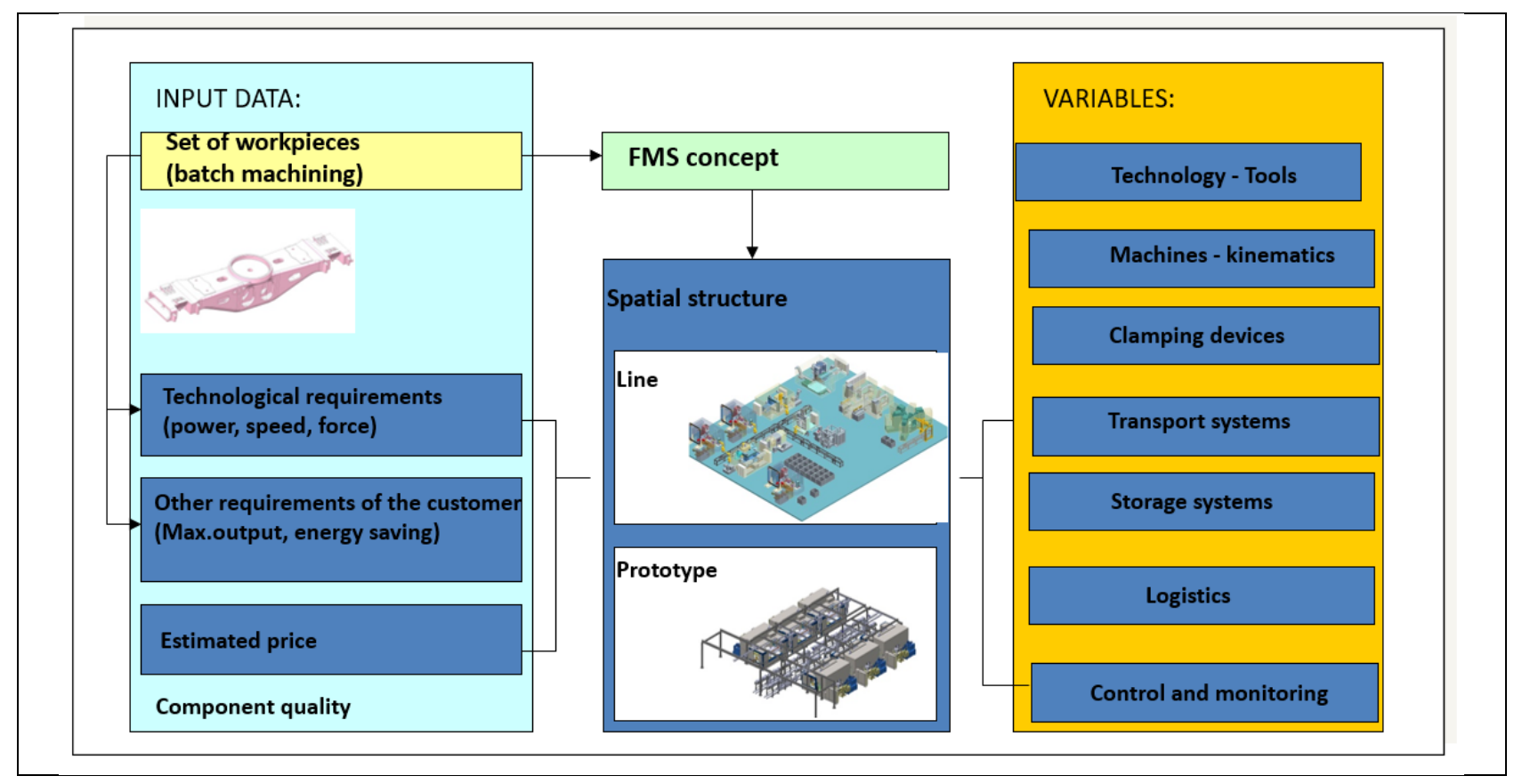

Fig. 4. Input data and variables when designing an FMS

Each FMS system is unique and adapted to the group of products for which it is intended. But at the same time, all systems are based on fundamental principles. Each device has an autonomous control system (CNC, PLC ..), Communication between them requires various types of compatible interfaces and protocols in order to smoothly exchange data, transmit and receive information about status, activities and work in a coordinated manner with the aim of optimal use of equipment and planned production.

\subsection{Parts characteristic, technology and tools}

Technological design and engineering of modern machining processes requires analysis of all technical and technological process parameters in order to model and define optimal conditions for machining processes and systems that will ensure cheaper, but at the same time more quality and profitable production. Process planning, as the main activity of technological preparation of production, begins with the study of design documentation, i.e. the study of the method of execution of products and its parts. contains certain stages, as well as methods and conditions for performing each stage in the production of each part. The main characteristics when choosing a processing strategy are:

- Workpiece material,

- Workpiece configuration, 
- Dimensional tolerances,

- Shape tolerances,

- Position tolerances,

- Quality of machined surfaces.

FMS is implemented to process not one part, but a family of similar parts, which implies the use of the principle of group technology, based on the knowledge that many technological stages contain certain similarities, and that by grouping similar problems, common solutions can be found. Thus, one technological group includes all parts that can be machined on one machine tool with the same accessories and tools, which means that they have a common technological base. By applying group technology, a certain standardization of technological procedures is achieved, which enables fast preparation which makes it possible to quickly prepare for the production of new products. At the same time, it is necessary to maintain the quality of production and and use to the maximum the capacity of the equipment. Based on group technology, grouping was performed on the example given in this article, which will present the process of creating a complex production system. . The selected product group is shown in Figure 5. This product group is similar in size and types of machining.

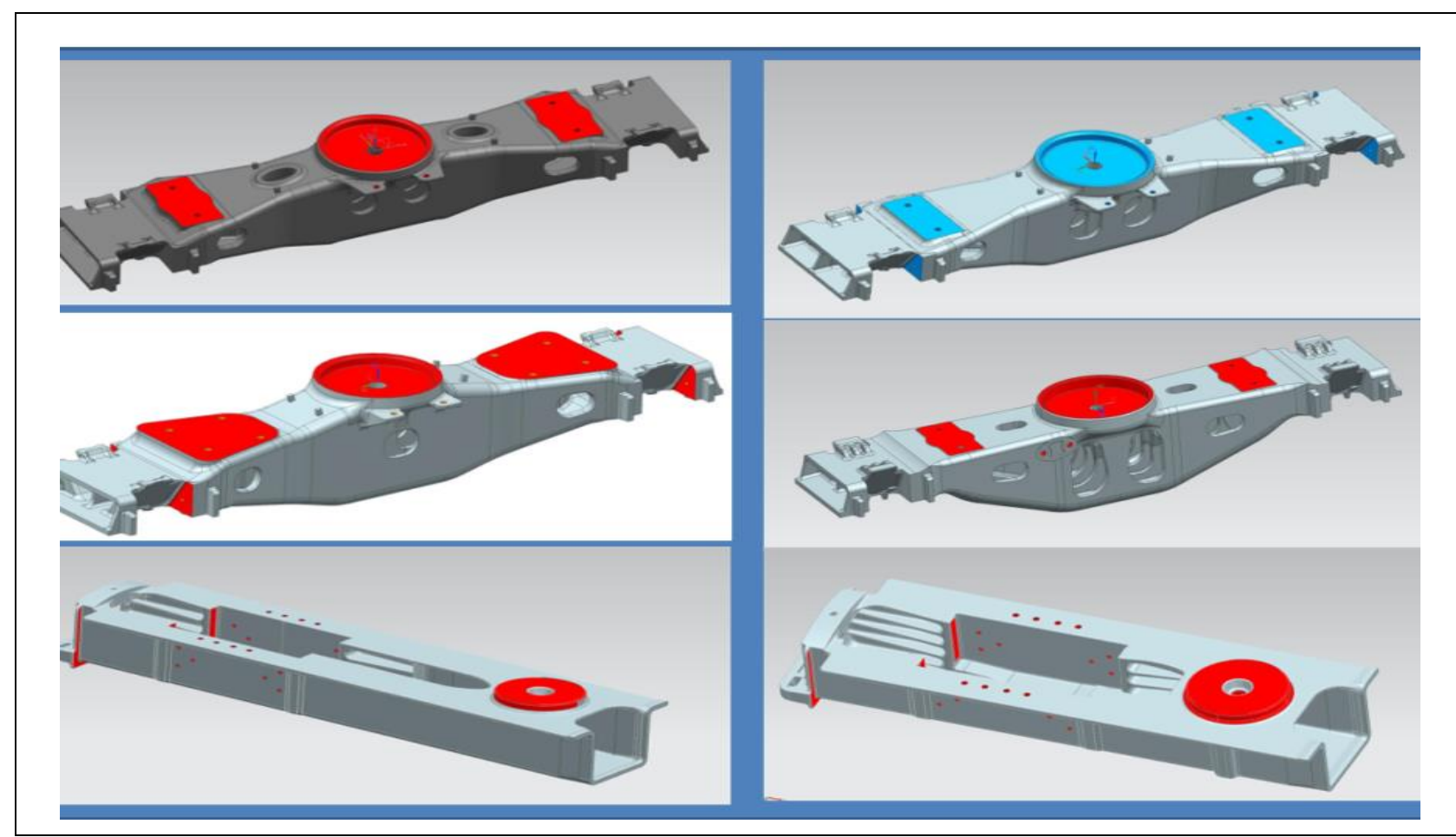

Fig. 5. Group of workpieces similar in size and types of machining (Brochures: Tikvin, Russia).

From the abovementioned group of products, a typical workpiece is defined, based on the geometric shape and accuracy parameters of which, the processing technology, principles and clamping methods, as well as the required types of tools are determined. The technology for this workpiece is the basis for all other workpieces from the workpiece family which can be expanded if necessary. 
Mulc, T.; Ciglar, D.; Staroveski, T. \& Klaic, M.: Integral Design Process of Flexibl...

Figure 6 shows the typical characteristics and tolerances for the workpiece. The stages of typical machining processes for the compilation of system technology are determined.To ensure the group machining of all parts, it is necessary to take into account all the operations and settings, with the help of which all working surfaces from the selected group of parts will be machined

Based on the performed technological analysis, the technological processes of machining each part of the same type of workpiece are defined, i.e. their sequence, cutting mode and cutting strategy. In this way, it is possible to optimize machining conditions, operations can be standardized and optimized based on batch size, available manufacturing equipment and requirements defined by the drawing.

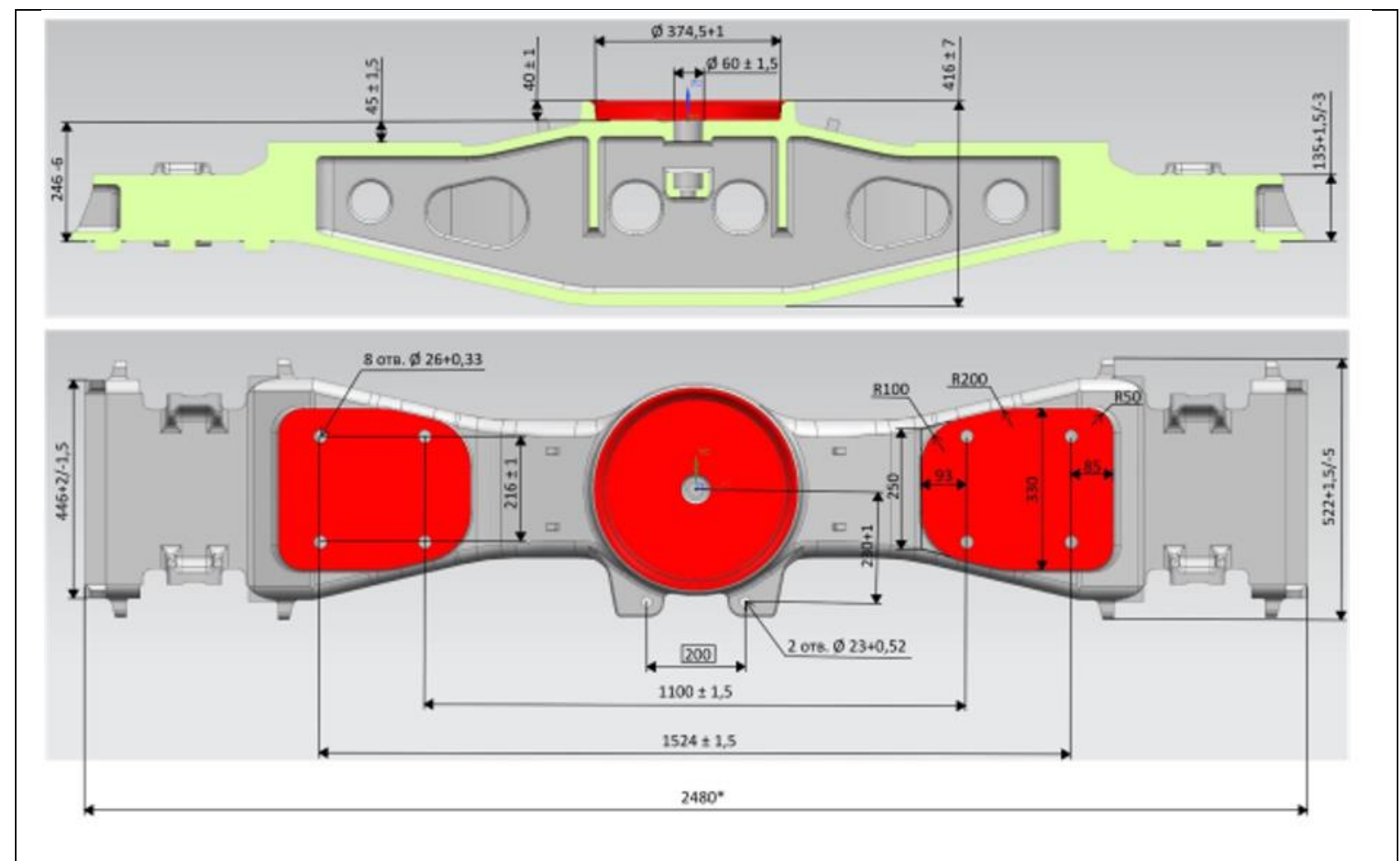

Fig. 6. Typical machining characteristics and tolerance structure (Brochures:Tikvin, Russia).

\subsection{Tool plans and cutting conditions}

The technological process is the basis of any production and sets the basic characteristics of the production process. The quality and cost of production largely depend on it. The tool is a very important element in this chain. Its quality, functionality, durability, stability largely determine the quality of the process, as well as future costs. Figure 7 shows the tool plans for all operations from the above product group 


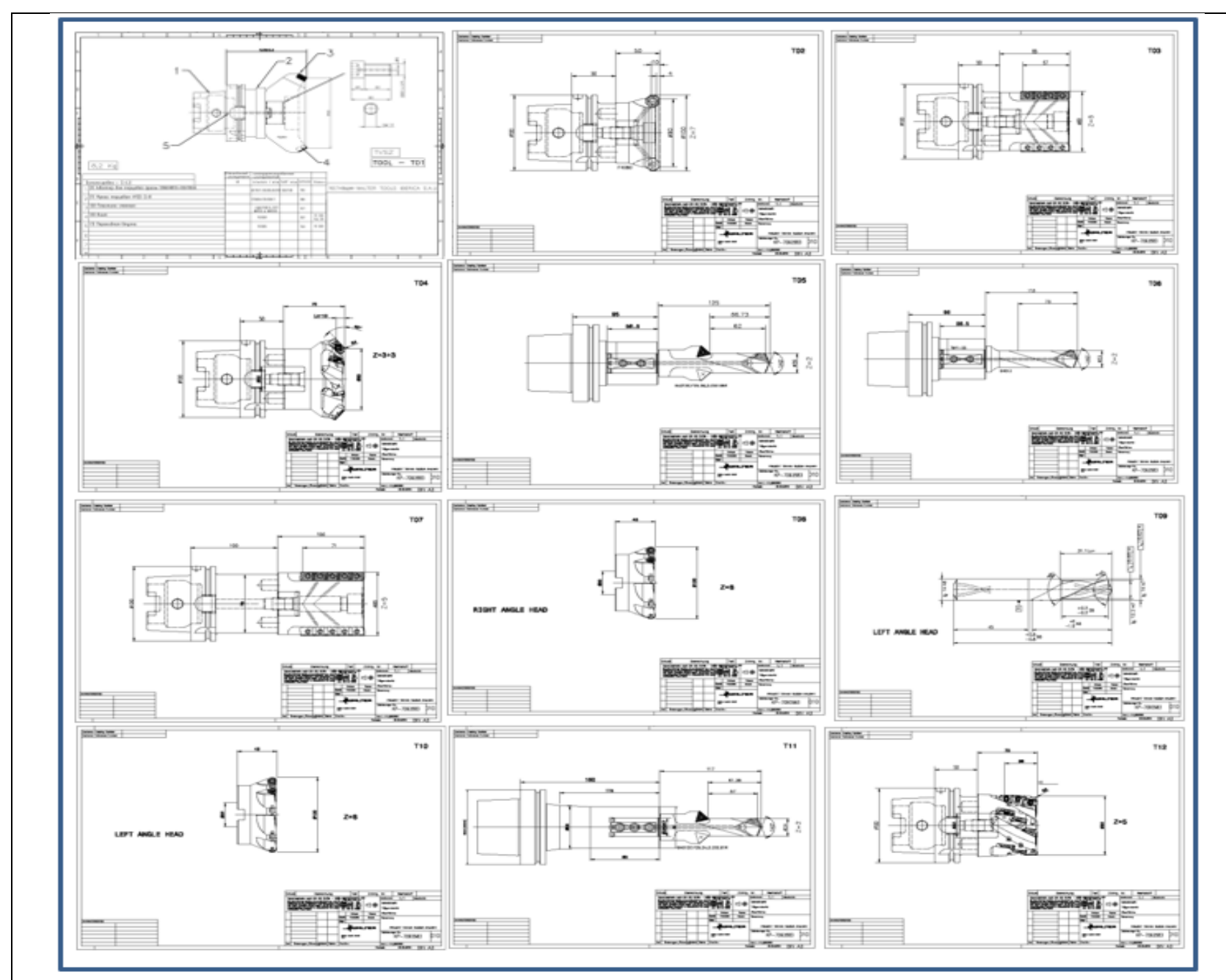

Fig. 7. Tool plans and technology for the product group shown in Figure 5 (Brochures: Riko, SAS-Strojogradnja, (2014), Croatia).

The price of the tool largely determines the price of the project and future costs, therefore the tool should be selected with particular care and, if possible, standard tools should be used.

\subsection{Selection or development of a dedicated flexible machine}

Technological analysis and selection of cutting tools is the basis for the selection or develepment type of the machine tool, clamping device and ancillary equipment which are directly involved in the implementation of the technological process of making a parts. The machine tools as basic elements of FMS essentially determines its spatial structure. The main features of machine tools are related to:

- Geometric characteristics (kinematic characteristics of the machine, working space, maximum possible dimensions, workpiece positions, etc.),

- Technological characteristics (rigidity of the machine construction, maximum rotational speed of the main spindle, power of the main spindle, feed rates and acceleration along the axes, number of tools, tool change time etc.), 
Mulc, T.; Ciglar, D.; Staroveski, T. \& Klaic, M.: Integral Design Process of Flexibl...

- Performance characteristics (accuracy and repeatability of the machine, productivity, flexibility, machining complexity, reliability of machine operation, maintenance etc.).

In addition to the above-mentioned basic characteristics of the machine, it is necessary to analyze the software aspects of the machining systems related to:

- Type and kind of control system,

- Handling and serving,

- Programming,

- Interface for CAD / CAM connection and computer-aided production,

- Machine process monitoring systems and machine diagnostics,

- Methods of preparation and adjustment of tools,

- Related measuring and machine tool,

- Equipment maintenance methods,

- Necessary organizational provisions,

- Space and energy needs,

- Completeness and quality of documentation.

\subsubsection{Kinematic structure of the machining center}

For the group of products presented in the previous chapter, the kinematic structure of the machine was selected on the basis of technological analysis, Figure 8. Since this type of machine was not available on the market, the configuration of the machines was chosen corresponding to the family of workpieces for which the FMS was designed.

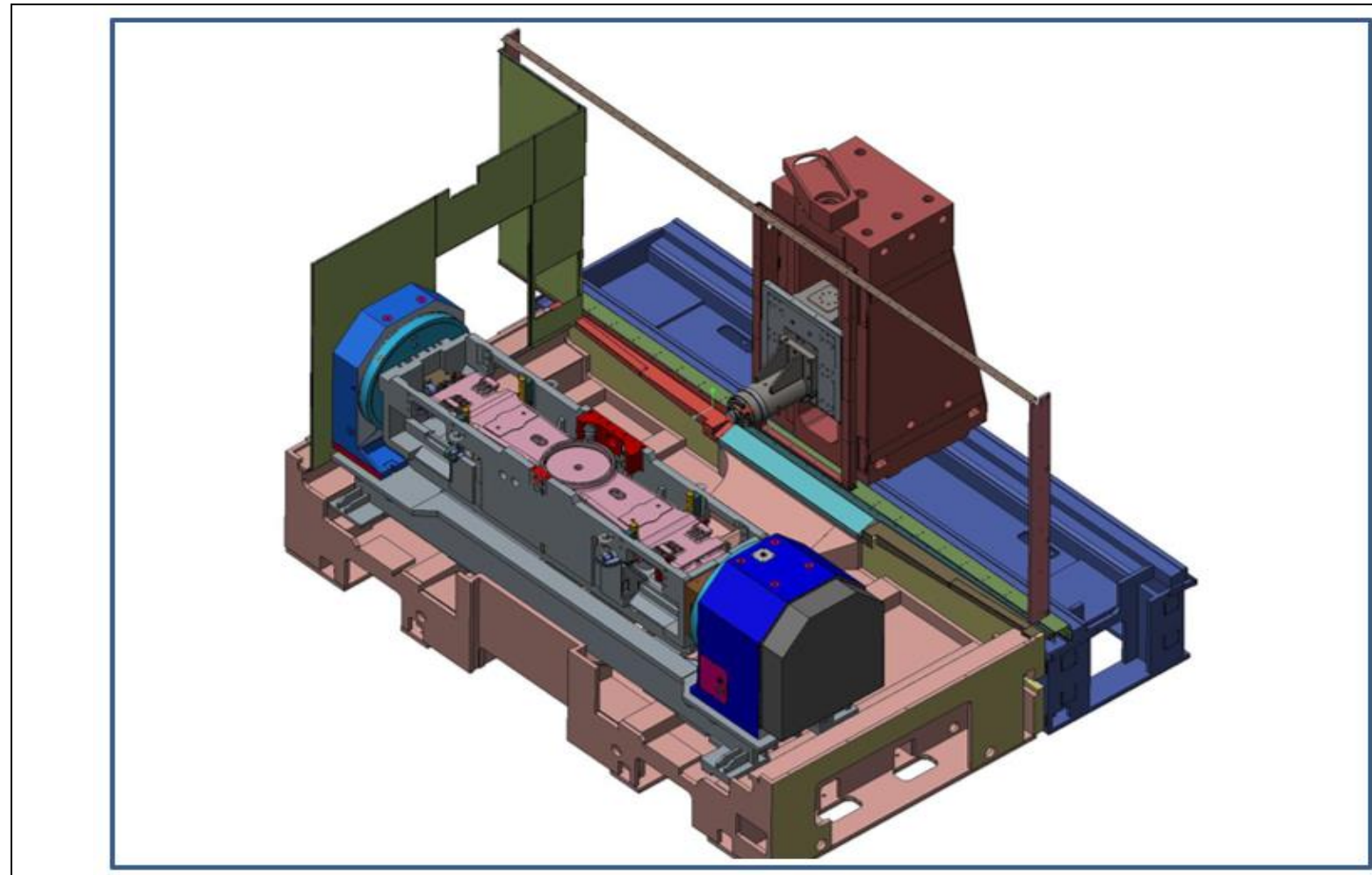

Fig. 8. Kinematic structure of the machining center (Brochures: Riko, SAS-Zadar. (2014). Croatia) 
The working area of the machine and the number of required axes were designed for the previously indicated workpieces. The sizing of the machine depends on the size of the workpieces and the capacities that must be provided for the stable processing provided by the technology. Tool magazine, automatic tool change are adapted to the tool sizes and weights indicated in the tool plans. The tool magazine should have an additional device for replacing angle heads weighing up to fifty pounds.

\subsubsection{Functional structure of the machining center and its features}

The characteristics of a machining center that can perform technological tasks depends on the selected kinematic structure. When designing the machining center, the following were analyzed and determined separately:

- Working area of the machine (depends on the dimensions of the workpiece and the ways of fastening the workpiece),

- Positioning accuracy of the machine (depends on workpiece tolerances),

- Spindle power and speed (depends on machining parameters),

- Tool type (depends on workpiece and machining type),

- Tool magazine capacity (depends on the number of workpieces, tool life and estimated machine run time),

- Number of controlled axes (depends on the type of machining, on the method and type of workpiece fastening),

- Loading the workpiece (depends on its weight, fastening and weight of the pallet),

- Type, size and number of pallets (depending on the workpiece and the material flow modes).

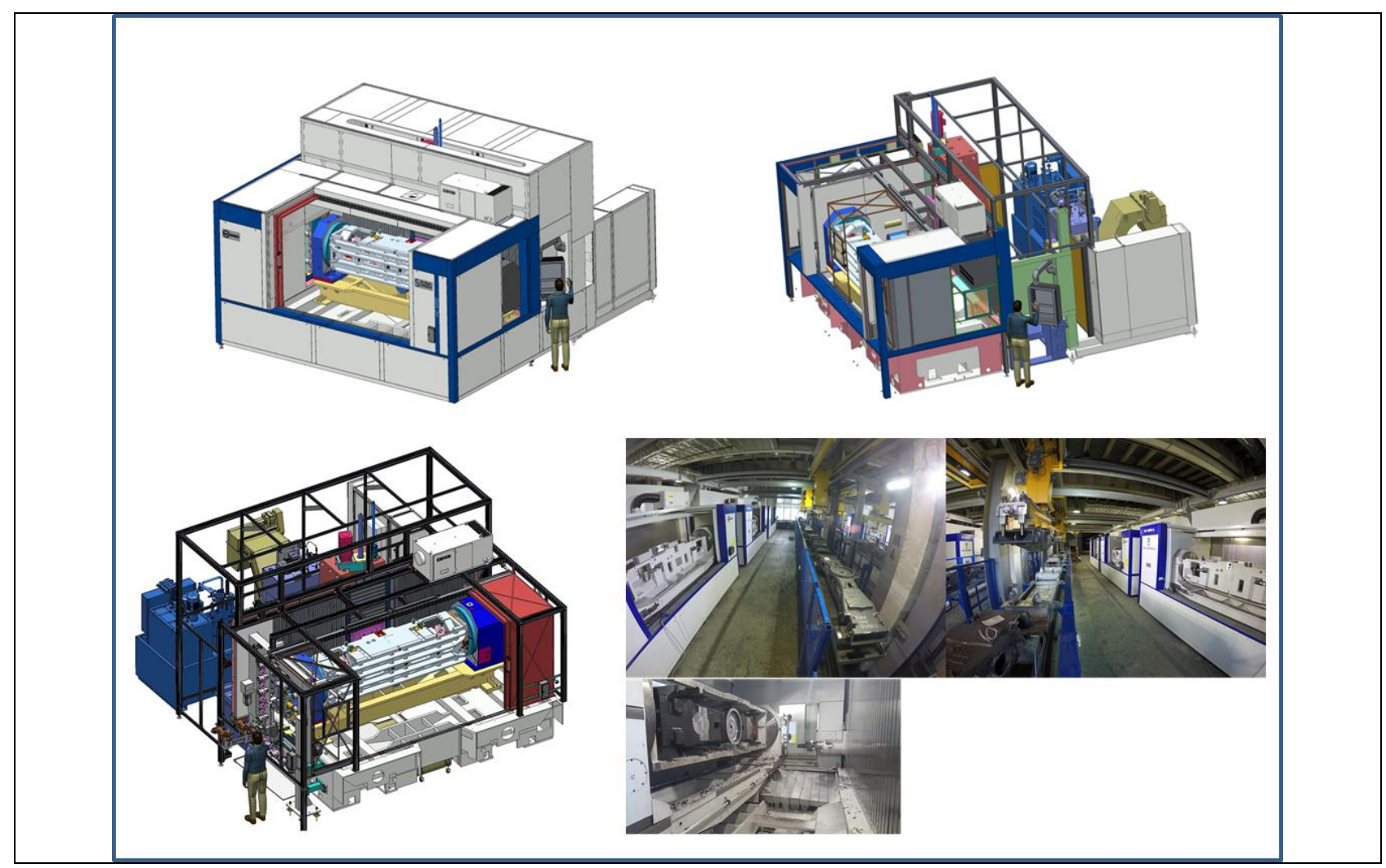

Fig. 9. Special machining center H3000A (Brochures: Riko, SAS-Strojogradnja, (2014), Croatia). 
Mulc, T.; Ciglar, D.; Staroveski, T. \& Klaic, M.: Integral Design Process of Flexibl...

Based on the analysis of all the above - mentioned parameters, the design of a special machining center $\mathrm{H} 3000$ that meets the above requirements was performed, Figure 9. The main technical characteristics are given in Table 2.

\begin{tabular}{|c|c|c|}
\hline CNC processing center & Type & HC $3000 \mathrm{~A}$ \\
\hline \multicolumn{3}{|l|}{ Work area } \\
\hline $\mathrm{X}$-axis $\bullet \mathrm{Y}$-axis $\bullet \mathrm{Z}$-axis & $\mathrm{mm}$ & $3200 \cdot 800 \cdot 1000$ \\
\hline Max. overall dimensions of the part diameter & $\mathrm{mm}$ & $2600 \times 800 / 800$ \\
\hline \multicolumn{3}{|l|}{ Work spindle } \\
\hline Tool clamping standard & & HSK-A 100 \\
\hline Drive S1 (100\% ED) & $\mathrm{kW}$ & 37 \\
\hline Speed range, standard & $1 / \min$ & 3000 \\
\hline Standard torque at S6 (40\% ED) & $\mathrm{Nm}$ & 1400 \\
\hline \multicolumn{3}{|l|}{ Feed / feed force / rapid traverse } \\
\hline Feed X-, Y-, Z-axes & $\mathrm{mm} / \mathrm{min}$ & $1-40000$ \\
\hline Feed force X-, Z-axis, $40 \% \mathrm{ED}$ & approx. kN & 30 \\
\hline Rapid traverse rotary table & $1 / \min$ & 12 \\
\hline \multicolumn{3}{|l|}{ Tool magazine } \\
\hline Number of tool slots (standard) & max. number & 40 \\
\hline Tool diameter / max. tool diameter & $\mathrm{mm}$ & $200 / 250$ \\
\hline Tool length max. & $\mathrm{mm}$ & 400 \\
\hline Tool weight max. & $\mathrm{kg}$ & 30 \\
\hline $\begin{array}{l}\text { Time from cut to cut / VDI } 2852 \text { / T1 (tool weight up } \\
\text { to } 12 \mathrm{~kg} \text { ) }\end{array}$ & approx. sec. & 9 \\
\hline \multicolumn{3}{|c|}{\begin{tabular}{|l|l|} 
Electric (Siemens 840D SI) & \\
\end{tabular}} \\
\hline Total power consumption & $\mathrm{kVA}$ & 140 \\
\hline
\end{tabular}

Tab. 2. Main technical characteristics of a special machining center

After the selection of the machine design for this product group, the concept of fastening and clamping devices was defined.

\subsection{Clamping devices}

Clamping devices are a very important element in the machining. The design of clamping devices is a complex task that must take into account the geometric configuration of the workpiece, tool plans and ensure ease of use, safety and costeffectiveness. They are specific and require a lot of professional knowledge and experience. They connect the tools on the one hand, and the machine with the workpiece on the other hand. They significantly affect the final result of the machining process.

Their task is to correctly position the workpiece with the required orientation in relation to the cutting tool or measuring device, or in relation to another component, as well as to ensure that the workpiece remains stationary during the process Clamp designing involves defining the basic configuration of the clamping device based on an analysis of all available information regarding the material and geometry of the 
workpiece, the required machining operations, the tool, the equipment involved in the process, and the operator. First of all, it is necessary to determine for each workpiece:

- type of clamping device,

- number of workpieces per clamping device,

- the orientation of the workpiece inside the clamping device,

- reference surface positions,

- clamping surfaces,

- support surfaces if required.

The clamping device should ensure repeatability, stability and stiffness of the workpiece in a precisely defined position. They are designed for a defined workpiece or group of workpieces. The design of clamping devices begins with the definition of the clamping plan, Figure 10. A clamping plan is made for each workpiece from the group of workpieces to be machined. Clamping, supporting, and orientation points are analyzed. Common points are found and it is tried to use a clamping device for several types of workpieces with minimal modifications.

Based on the clamping plan, the construction of clamping devices begins. When constructing the clamping device, both the tool plans and the processing that is carried out should be taken into account. Clamping devices should be designed in such a way that they can receive as many workpieces as possible with minimal adjustments.

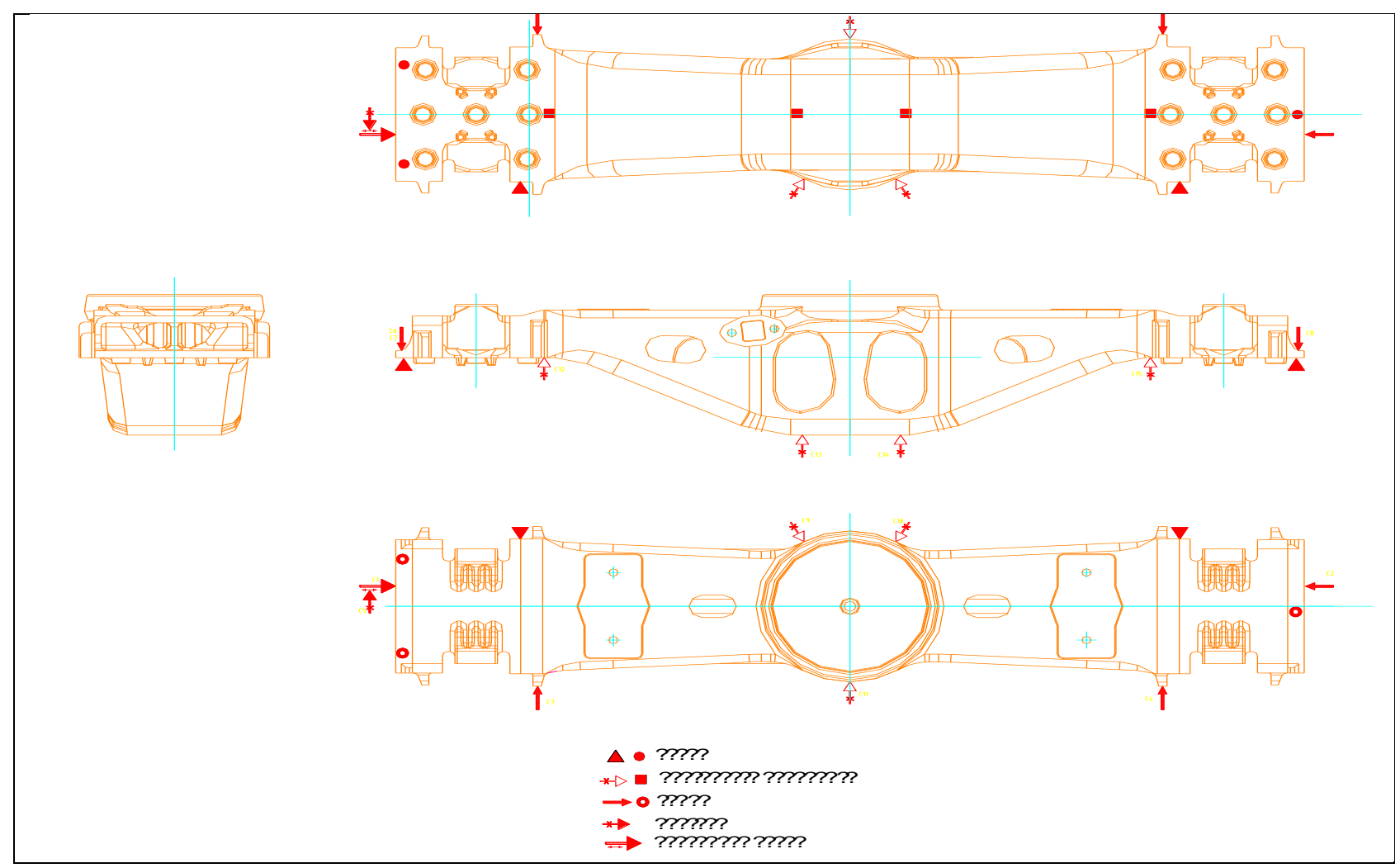

Fig. 10. Clamping plan for one of the workpieces

One of the manufactured clamping devices is shown in Figure 11. It can, with minimal adjustment, receive most of the workpieces from the workpiece family for which the FMS is made. 
Mulc, T.; Ciglar, D.; Staroveski, T. \& Klaic, M.: Integral Design Process of Flexibl...

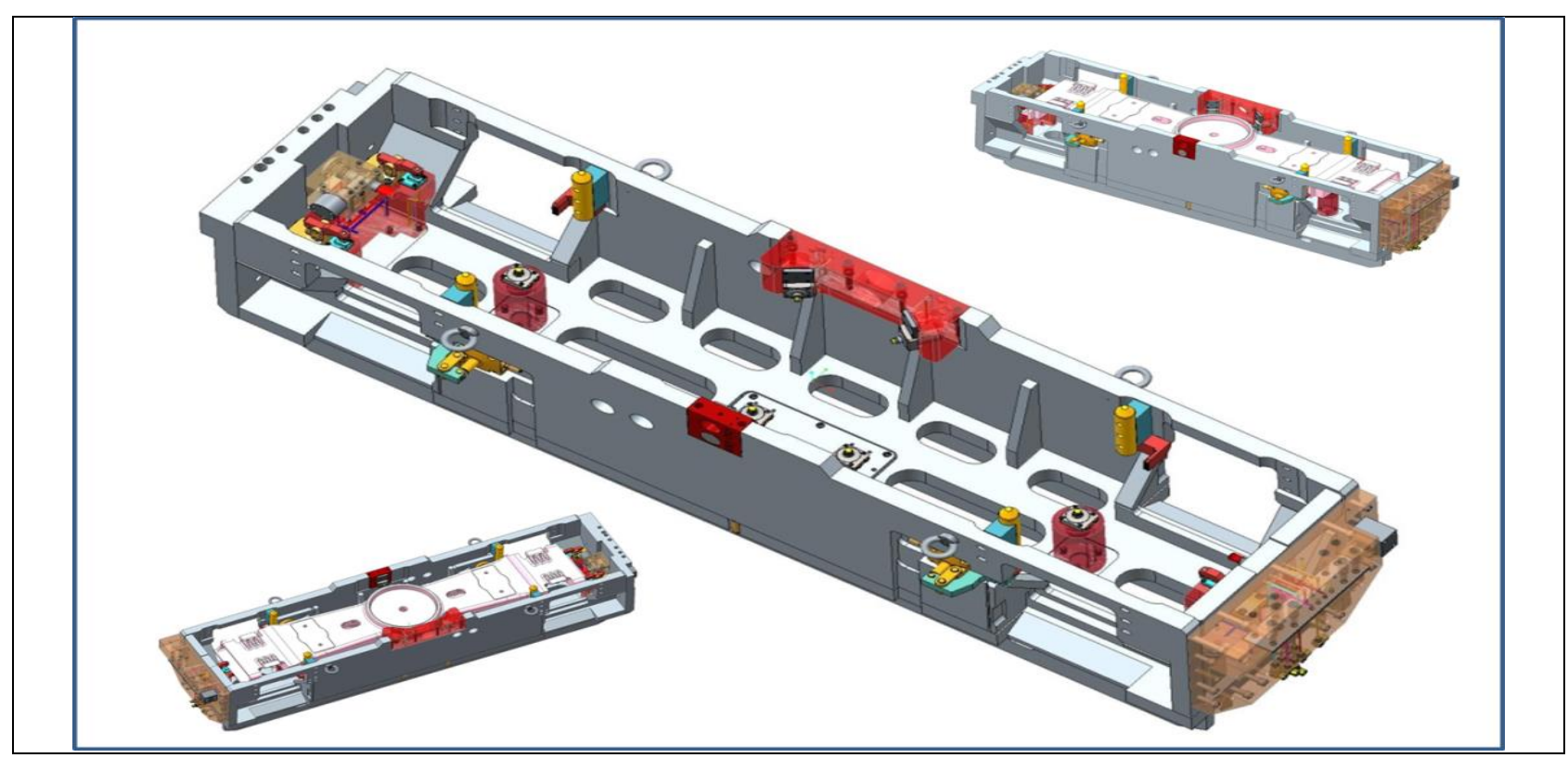

Fig. 11. Clamping device (Brochures: Riko, SAS-Strojogradnja, (2014), Croatia)

In this particular case, during the design of the FMS the Customer had a need to further expand the capabilities of the system for a new set of workpieces. This product group required the application of a pallet system so that the system that was planned to be manipulated by the workpieces was expanded and supplemented with the pallet system during the design phase, Figure 12.

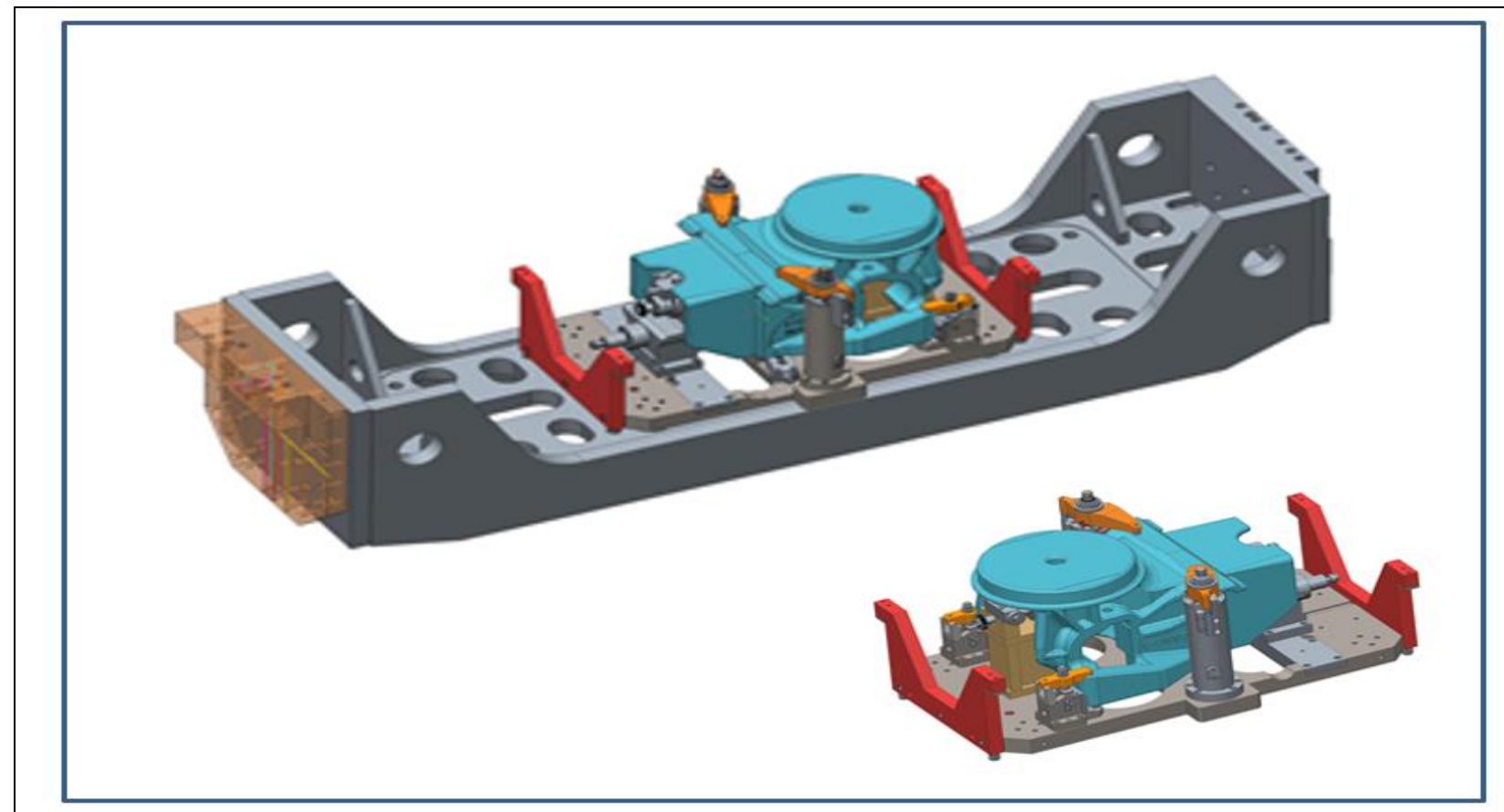

Fig. 12. Pallet system concept with zero-point clamping system (Brochures: Riko, SAS-Strojogradnja, (2014), Croatia).

The application of pallet systems has significantly expanded the scope of FMS, with a new group of products. The flexibility and ability to expand the capabilities of the FMS has been increased. 


\subsection{Storage structure and transport system}

An essential component of FMS is a system for storing and handling materials and tools. The transport system carries out organizational, temporal and spatial connection of technological, control, and all other processes related to the material moving through the production system during the production cycle. The handling and storage system should ensure:

- transport of working parts (pallets) between machines,

- manipulation with different types of workpieces,

- temporary storage of materials (workpieces, tools etc.),

- convenient access for loading and unloading workpieces.

Given the variety of products, the design of the transport system and storage is a complex task and depends on the structure of the concept of FMS, the complexity of the task, the size of the workpieces. The transport system intended for the development of the FMS dedicated for processing the previously described workpieces is shown in Figure 13. gantry manipulators located in front of each machine, and a central conveyor system with rail trolleys that move workpieces between the storage and the processing area.

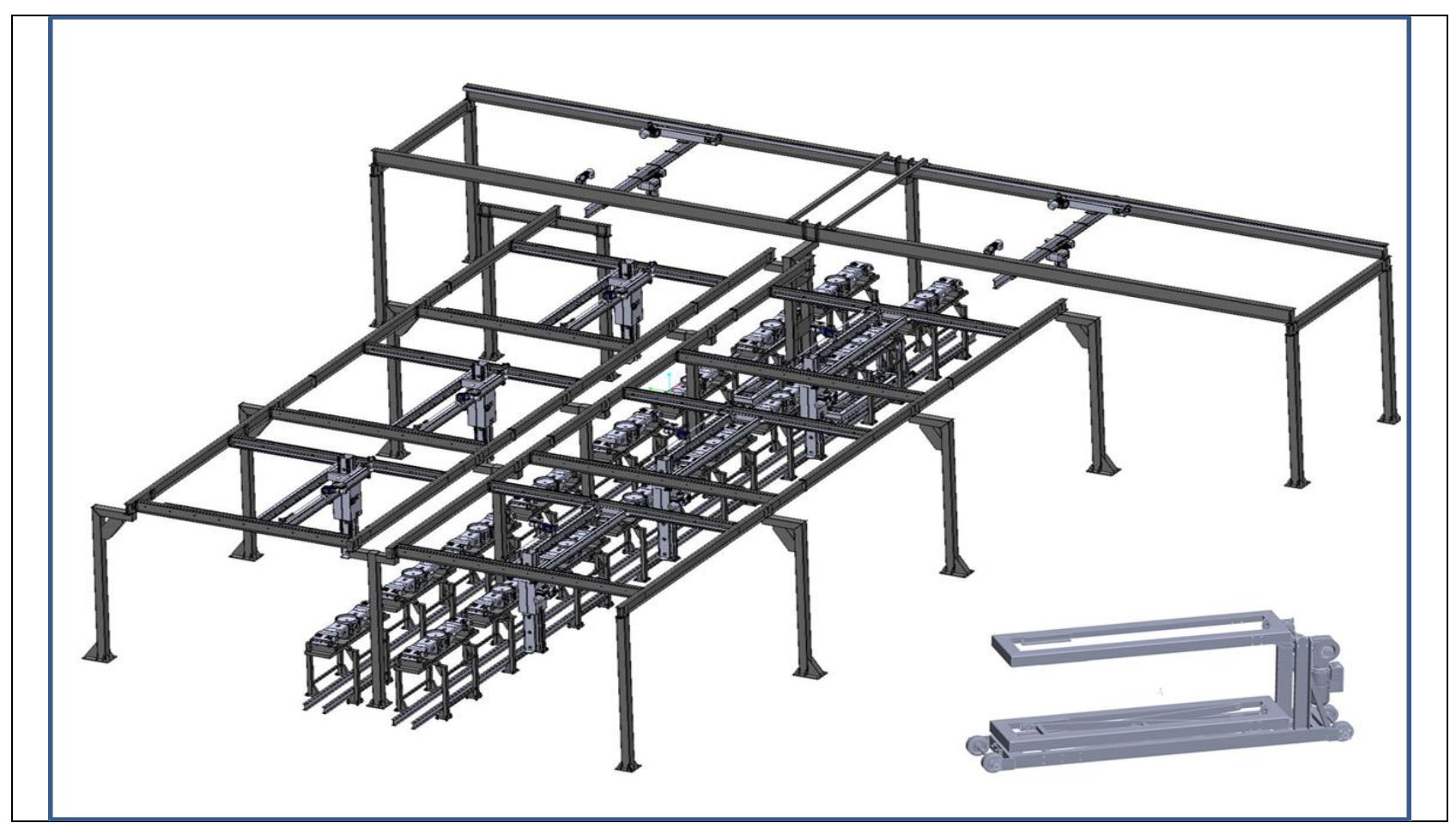

Fig. 13. Manipulation system (Brochures: Riko, SAS-Strojogradnja, (2014), Croatia)

\subsection{Spatial structure of FMS}

Based on previous technological analyzes, defining the number of machines for the required performance of the available space and required capacity, the spatial structure of the FMS is formed, shown in Figure 14. Taking into account the efficiency of the equipment, 6 machines were planned. The FMS described in the previous chapters is designed to produce 12 pieces per hours, or 250 pieces per day. The machining time of the workpiece with the longest machining cycle is $29 \mathrm{~min}$. 


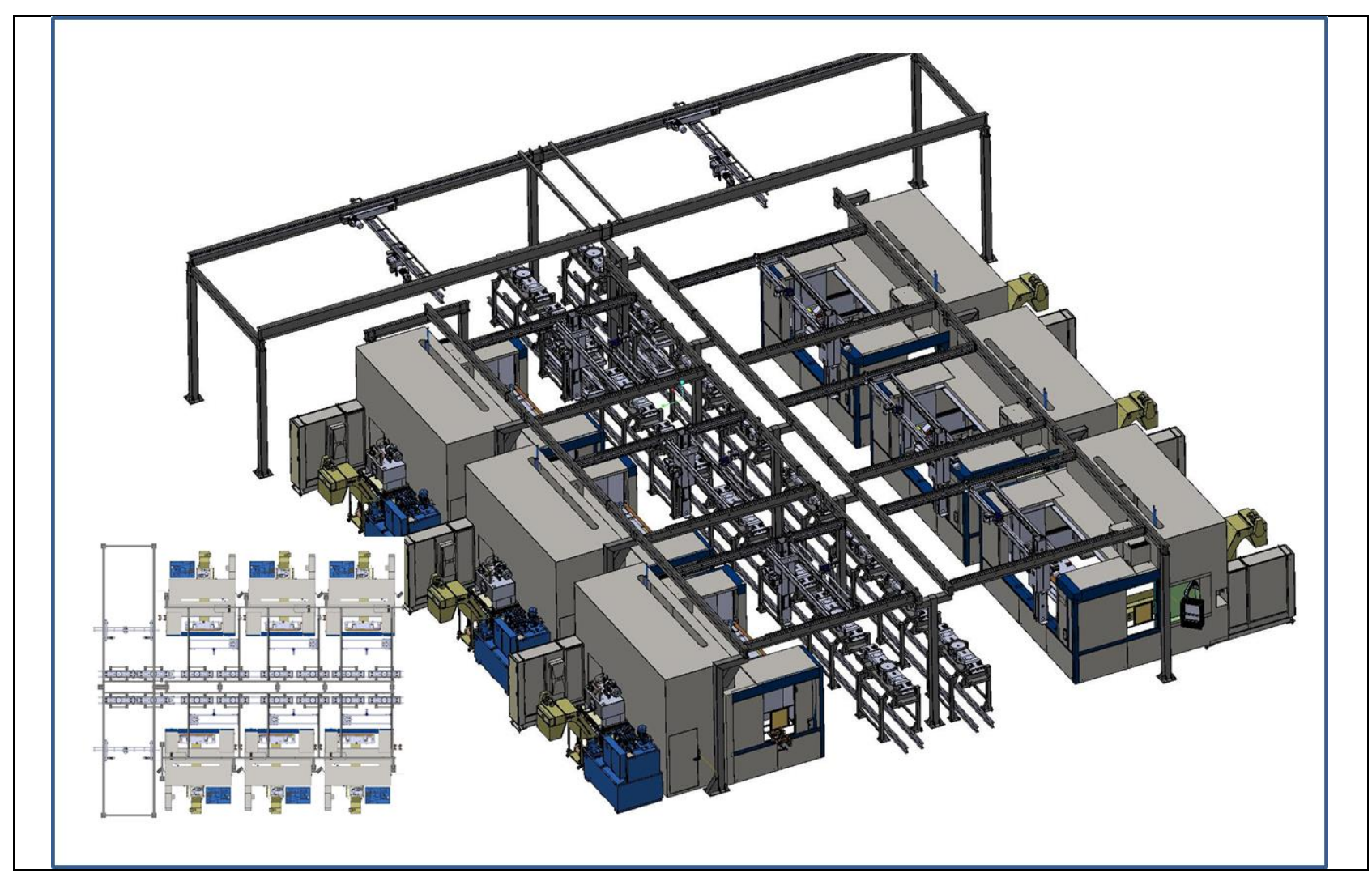

Fig. 14. Flexible machining system for the workpiece family (Brochures: Riko, SASStrojogradnja, (2014), Croatia).

The FMS shown provides an annual production of about 50,000 workpieces from the workpiece family for which it is designed. The expansion of FMS with pallet zeropoint systems has significantly increased the flexibility and ability to clamp a larger number of different workpieces.

\subsection{Control and flow of information through FMS}

Logistics software controls the flow of materials in the production system. It activates transport devices by means of certain transport orders, mainly consisting of data on the zero position, the destination position and the object being transported. The software contains data on transport devices and their structure. Logistics software for control of all production processes distributes information depending on the state of individual autonomous systems in accordance with organizational data (display of pallet occupancy, process completion, machine status, position of transport devices, storage system occupancy status, future system activities, preparation station status, etc.).

The logistics software sends only one order to the transport device at a time. Only when this order is reported as completed, the next order is issued. The loading and storage station works separately, but also sends and receives information from the logistics software about its condition. All objects that are in the process of transport and that are moved and travel through the system are coded (pallets, clamping devices, tools, etc.) and have a record of their condition. 


\section{Conclusion}

The process of creating a flexible manufasturing system is not technologically simple and inexpensive. It requires extensive professional work and knowledge of all aspects of the formation of complex systems. Strategic decisions must be timely, well thought out, analyzed and optimized. Subsequent partial solutions cannot eliminate structural errors. There are many issues requiring solution and optimization, from the very idea and technology development to direct manufacturing, installation, transportation, logistics, and service. Therefore, when forming a concept, it is necessary to have a global vision of the project, taking into account all its aspects (technological stability, quality, productivity, flexibility, price) in order to successfully design and form the optimal structure of the FMS for a particular group of products.

An integrated approach to the development of complex systems is a necessary condition for the construction of complex production systems. At all stages of design, the quality of technological solutions should be considered, taking into account the need for modularity and scalability of the system as a basis for current and future needs.

It is necessary to take into account the mechanical, electrical and software interface, the ability to use "intelligent" sensors and diagnostic tools to register and evaluate important events and the current state of the system and environment, the openness of software extensions for external knowledge, etc.

In order to ensure flexibility and a high level of integration in the architecture of the FMS control system, which is the basic integrating element, it is necessary to decompose the control system into subsystems and the subsystems further into modules. A modular approach should expand the capabilities of the system for future products.

Therefore, the main feature of production systems is adaptability, or flexibility, at all levels, which is a fundamental requirement arising from the needs of the market. It means systems thinking from an individual process, a machine through production cells, to flexible systems. Flexibility requires an integrated approach that involves looking at the problem at the level of:

- Product - personalization, local production, flexibility at a low price,

- Process - networked production, modular structure,

- Business models - fragmentation of the value chain,

- Skills - interdisciplinary thinking (engineering knowledge) is key.

\section{References}

Abele, E.; Worn, A. \& Kuhn, S. (2007), Design Princips for Reconfigurable Machine Tools, 11th International Scientific Conference on Production Engineering CIM 2007, Abele,E; Udiljak,T. \& Ciglar,D.(Ed.), pp. 1-13, ISBN 978-953-97181-9-8, Biograd, 13th - 17th June 2007, HUPS, Zagreb.

Brochures: Riko, SAS-Strojogradnja, (2014), Croatia.

Brochures: Soflex.

Brochures: Tikvin, Russia. 
Mulc, T.; Ciglar, D.; Staroveski, T. \& Klaic, M.: Integral Design Process of Flexibl...

ElMaraghy, H.A. (2005). Flexible and reconfigurable manufacturing systems paradigms, International Journal of Flexible Manufacturing Systems, Vol. 17. , No.4, pp.261-276.

Haar,J. (2019), Digitalisierung der Fertigung - Herausforderungen und Losungenmav, MAV Innovationsforum 2019, März | 2019, p.84-85.

Hermaste,A; Riives,J.; Sonk,K., Sarkans,M. (2014), Design Principles of Flexible Manufacturing Systems, 9th DAAAM Baltic Conference, 24-26 April 2014, Tallinn, Estonia, pp.92-96

Kaut,M. (2018), Großbauteile automatisiert und flexibel bearbeiten, NCF-februar 2018, pp.22-24

Koren,Y. (2010). The Global Manufacturing Revolution: Product-Process-Business Integration and Reconfigurable Systems, John Wiley and sons, New Jersey.

Mehrabi, M.G.; Ulsoy, A.G.; Koren, Y. \& Heytler, P. (2002), Trends and perspectives in flexible and reconfigurable manufacturing systems, J Intell Manuf 13(2):135-146

Mehrabi,M.G. ;Ulsoy,A.G. \& Koren,Y. (2000). Reconfigurable Manufacturing System: Key to Future Manufacturing, The University of Michigan, Ann Arbor, MI 48109-2123

Vukovic,A.; Ikonic,M.;Dobovicek,S. (2010). Reconfigurable Manufacturing System and the Need for New Taylorism, Eng.Rev. 30-2 , pp. 71-82 